\title{
Embedded BIPV Module-level DC/DC Converters: Classification of Optimal Ratings
}

\author{
Simon Ravyts, Mauricio Dalla Vecchia, Giel Van den Broeck, \\ Georgi H. Yordanov, Juliana Emanuella Goncalves, Jens D. Moschner, \\ Dirk Saelens, Johan Driesen \\ KU Leuven - Energy Ville \\ Thor Park 8310 \\ 3600 Genk \\ Belgium
}

10

\section{Abstract}

Building-integrated photovoltaics (BIPV) is seen as a key technology to reduce the environmental impact and net power consumption of buildings. The integration of PV into building components, such as façade, window, roof or shading elements, leads to a distributed generation over the building envelope with a profound impact on the electrical installation. Designing the electrical system with string inverters and a possible wide variety of module sizes and technologies is a challenging task. To overcome this issue, Module-Level Converters (MLCs) can be used. A supplementary benefit is that the consequences of partial shading can strongly be reduced. This paper investigates whether the current generation of MLCs is suited for embedment in facade BIPV modules. The PV output is categorized and compared to the input parameters of the converters. Besides the discrepancy between the physical dimensions of the converters and the desired installation location, thermal and electrical measurements on a prototype BIPV curtain wall element reveal that daily energy losses can be as high as $50 \%$ due to thermal overload when used in a moderate climate such as Belgium. The paper concludes by discussing further standardization of BIPV module-level converters.

Keywords: BIPV, DC/DC converters, module-level converters, LVDC, curtain wall

Preprint submitted to Journal of Renewable Energy

June 4, 2019 


\section{Introduction}

The use of Building-Integrated Photovoltaics (BIPV) is facilitated by de-

15 envelope. A large variety of BIPV elements are already available on the commercial market such as windows, roof tiles or façades [1, 2, 3].

European legislation endeavors to further increase BIPV penetration via several directives such as the Strategic Energy Technology (SET) Plan and the buildings are near Zero Energy Buildings (NZEB) from 2020 on [4, 5]. The integration of BIPV into building façades is seen as a key solution to achieve this goal in an urban context where the available roof area is scarce compared to the abundance of available vertical surfaces [1, 6].

Given the commercial profitability of companies in the sector and several pilot projects around the world, BIPV can be seen as a promising technology. There is however still a strong research interest to further drive down costs and to improve the technical aspects of BIPV modules and BIPV installations. Technological advancements show that both the efficiency and appearance of BIPV solar cells continuously improve over the years for transparent [7] and non-transparant applications [8, 9]. Also the impact of BIPV on the thermal performance of the building is recently gaining more interest [10, 11, 12].

Façade BIPV systems are currently evolving in two directions. To date, most buildings with BIPV are entirely custom-designed and the appearance 35 and prestige of the project are considered more important than the energy yield and payback time. Next to the currently existing market, the need for standard off-the-shelf BIPV modules has been identified [3, 13, 14]. Off-theshelf modules are expected to represent a future mass market for façade BIPV. Several practical obstacles however still obstruct large-scale penetration of these standardized BIPV modules such as the integration of the electronics and their reliability [15], and an easy practical method to electrically interconnect the BIPV modules from one to another. 
This work will focus on BIPV curtain wall elements with integrated (embedded) DC/DC Module-Level Converters (MLCs). By integrating the converter in the frame of the BIPV module, local Maximum Power Point Tracking (MPPT) can be achieved. This approach leads to lower engineering effort to design the electrical system, lower installation costs during construction and a higher overall system efficiency. This concept and the advantages thereof will be explained in further detail in section 2. Part of the curtain wall element is glazing whereas the other part is the PV module. Since several types of PV technology can be used in this curtain wall element, section 4 will investigate the two most commonly used BIPV materials for a case study building. Focus is put on the differences in output voltage, current and power and a classification is proposed. This serves as an input for section 5 where commercially available MLCs are compared and their suitability for integration is evaluated. In section 6 the need for dedicated BIPV MLCs is further formalized by a proposed standardization of the MLCs and a discussion the preferred PV technology. Section 7 concludes this paper.

\section{Modular BIPV systems}

60 2.1. Concept

The concept of modularity in BIPV curtain walls was already introduced by Goncalves et al. [1] but further focus on the electrical aspects of this concept is presented here. To facilitate façade installation, pre-fabricated curtain wall elements are extensively used in the construction sector. The outer frame is typically an extruded aluminum frame whereas the outer surface can be made of a large variety of materials such as glass, plastic or metal. Due to its simplicity, installation costs can be reduced and the architectural freedom to design an appealing façade is only minorly restricted. The latter is an important aspect to consider as low creative freedom could hold back architects from using BIPV 70 technology [16]. 
Typically, curtain wall modules are divided into a transparent and a nontransparent part, as shown in Fig. 1. The non-transparent part is usually located between two adjacent floors to hide the technical equipment which is above the false ceiling. For optimal PV efficiency, the focus in this work is on replacing the non-transparent passive part by an energy-producing (active) element. Placing PV modules in curtain walls is already undertaken by several companies in the BIPV industry [2, 3]. Current projects however remain an entire custom design which is a consequence of and maintained by a lack of standardization in the sector. Not only the curtain wall dimensions vary over different projects but also the design of the electrical installation is challenging as string inverters are used.

The large majority of BIPV literature still reports using string inverters [17, 18, 19, 20, 21, 22, 23, 24, 25, 26, 27, 28. An exception to this is the Copenhagen International School in Denmark where micro-inverters are used

85 29]. To use a string inverter, panels with similar I-V characteristics and shading profiles need to be selected by the electrical design engineer and cabling needs to be done on site by a skilled construction worker. Both aspects increase the amount of manhours in a project, which adds to the costs of the installation. Next to the capital investment itself, the energy production and thus revenues 90 can be lower in contexts where partial shading occurs because shaded cells limit the performance of the entire string. Energy losses in the order of 5-35\% are reported as a consequence of partial shading in BIPV systems [30, 31, 32, 28].

To overcome the problems due to partial shading, module-level MPPT is preferred over string-level MPPT. This can be done by MLCs which should then be integrated in the aluminum framework of the BIPV module. Another major advantage of this approach is that the electrical network layout and thus the cabling can be further simplified if all modules are connected in parallel to the same bus. This electrical topology is shown in Fig. 2 and was first introduced in [33. Note that a Low-Voltage DC (LVDC) architecture is assumed instead of 100 the more conventional AC system. In applications such as datacenters, LVDC systems are already employed as they offer specific advantages such as a higher 


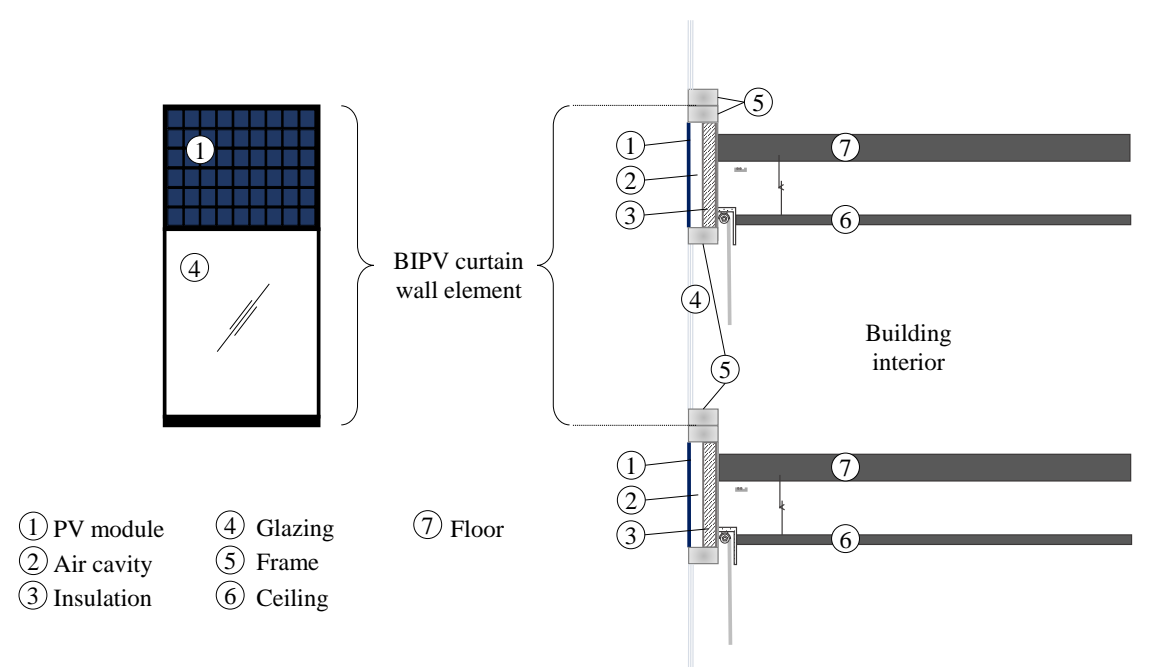

Figure 1: Front view and vertical cross-section of the prototype BIPV curtain wall element with indication of the used materials.

overall efficiency, lower costs and a higher reliability due to fewer components. For office buildings in general, the use of LVDC is preferable regarding the high penetration of DC consumers and because higher system efficiencies can be obtained by reducing the amount of conversion steps.

From an economical point of view, the main drawback of using MLCs is the higher price per installed Wp compared to string inverters. However, it is expected that this disadvantage will be overcome in the near future as converter prices will decrease due to mass production 33 . Next to this, integration of the MLC in the frame leads to a strong reduction in man-hours. When converter integration and wiring is part of the pre-fabrication process, the mechanical and electrical installation can occur simultaneously and be done by a construction worker. An electrician is only required to connect the BIPV feeder to the main LVDC bus.

From an engineering point of view, frame-integration poses however several practical difficulties that need to be overcome. Placement in the hollow cavities of the aluminum frame is preferred over more conventional attachment to the rear side of the PV panel because insulation materials are placed behind the 


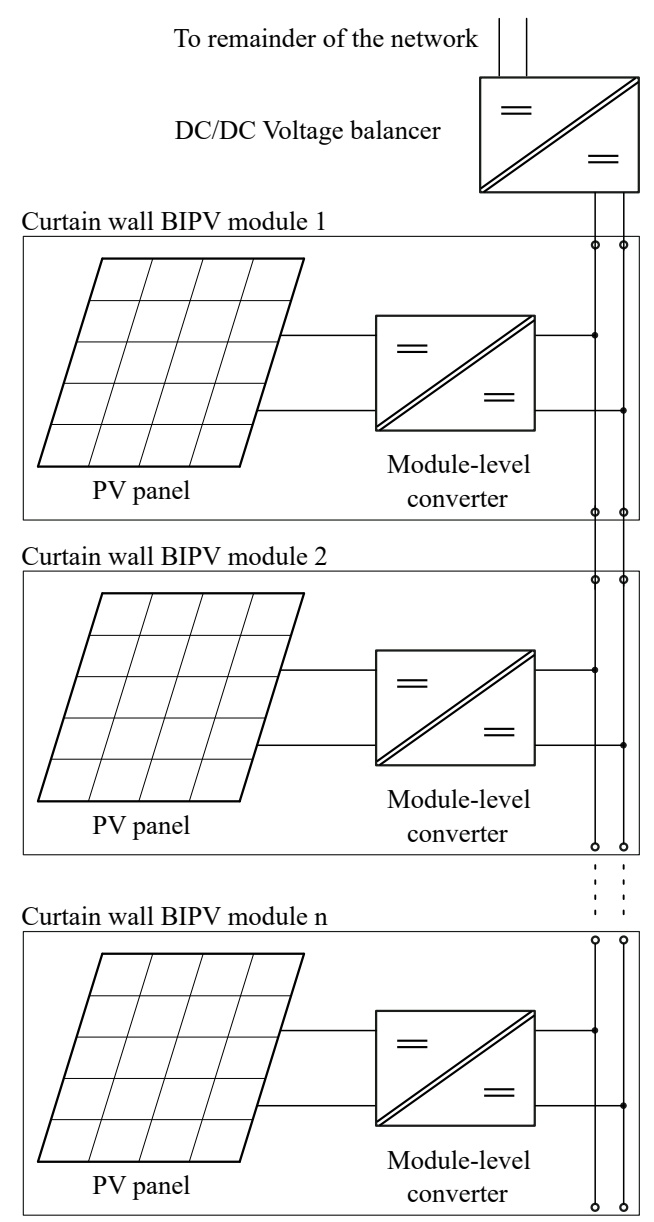

Figure 2: A schematic overview of the electrical installation of curtain wall BIPV modules connected to a LVDC grid - All elements have a dedicated MLC, of which the outputs are connected in parallel to the same DC bus that runs from one module to another. The bus voltage is stabilized by a central DC/DC voltage balancer. 
PV panel in façade applications. A specific form factor is thus required: an elongate rather than a square design. The thermal design is also a concern due to the limited cooling possibilities and the high ambient temperatures that occur near the PV panel. This could lead to eventual reliability problems due to the high steady state temperature and the large temperature swings. Further issues related to the power electronics converters will be discussed in section 5

Another positive consequence of using exclusively MLCs in the BIPV modules are potential reductions in the fabrication costs of the PV panel. PV modules now need to comply with standards and test procedures which stem from conditions that occur in string operation such as IEC61215 and IEC61730. Series connection of the panels leads to a higher system output voltage. Decent electrical insulation is critical as for example flash-over can occur between a pole (+ or -) of the PV panel which is at a high potential and the metallic frame, which is earthed and thus on ground potential. To prevent this from happening, sufficient distance needs to be respected between the frame and internally electrical conducting components such as the cells and conduction strips. Commercial PV panels are tested for systems up to 1000 or even $1500 \mathrm{~V}$ breakdown voltage. If the BIPV modules are restricted to work with MLCs, test standards can be relaxed since the max voltage between the frame and the PV output terminals is restricted to the voltage of the panel itself. As a consequence, the energy density of the module can be increased as the cells can be placed with less clearance with respect to the edges of the module. For the same output power, this leads to a lower cost per watt peak of the modules due to savings in materials (smaller total surface) and packing/transport. The use of a lower DC voltage also reduces the risk on arc-faults that could lead to fire.

\section{Methodology}

An example layout of a curtain wall module is shown in Fig. 1. A prototype measuring $270 \mathrm{~cm}$ by $109 \mathrm{~cm}$ was built and installed in the façade of a test building to measure the electrical output and to verify and validate BIPV mod- 
els. This prototype BIPV module is based on an actual curtain wall element of a building in Brussels, Belgium. The mechanical properties of this curtain wall module serve as an example in the remainder of the manuscript. The actual prototype has a fixed area dedicated for PV cells. In this manuscript we investigate the impact of changing this PV-decicated area from 0 to $100 \%$, as can be the case in actual designs. Furthermore, the electrical properties of different PV technologies (c-Si, c-Si half cells and CIGS thin film) are evaluated.

The obtained results are then compared to the voltage, current and power range of commercially available MLCs. As explained in Section 2, DC/DC converters connected to a LVDC grid are envisioned for the modular BIPV approach. To the best of our knowledge, there is however only one manufacturer that designs Parallel Power Optimizers (PPOs) and it was therefore decided to include Micro-Inverters (MIs) and Series Power Optimizers (SPOs) in the comparison to broaden the overview.

Not only the electrical requirements for BIPV curtain wall modules are investigated. Also the possibility to integrate them in the framework of the BIPV module is checked by comparing the dimensions of the MLC to the available space in the aluminum tubes of the curtain wall element. Besides the dimensional requirements, this environment is harsher from a thermal point-of-view. Thermal measurements that were obtained from our test setup indicate temperatures that exceed the maximum operation limit of the converters. The resulting daily energy loss due to converter autoshutdown is calculated by combining the thermal measurements with the electrical measurements of our test site.

More details on the module itself, the measurement setup and experimental results regarding the electrical and thermal performance can be found in [10, 11, 12.

\section{Output range of modular BIPV}

To evaluate the performance and rating of MLCs, this section provides an overview of the expected output range of modular BIPV systems. The output 
voltage, current and power of the BIPV module needs to correspond with the input rating of the MLC. Compared to mainstream c-Si 60- or 72-cell PV panels, a much larger variety of output ratings will be observed for modular BIPV systems due to the difference in size and thus in the amount of cells. Even more complexity is added by shingled half and quarter 6" cells, 5" cells, as well as by CIGS and CdTe thin films that have very different per-cell $V_{o c}$. This section will quantify this difference and serve as input for Section 5.

\subsection{Materials and results of specific test setups}

Practical experience with BIPV elements was built up over two projects, namely the EFRO funded SolsThore and INTERREG funded PVOpMaat project. The obtained results will be discussed in this section.

The two main BIPV technologies are c-Si and thin film (TF). Six inch industrial c-Si cells can have rated short-circuit currents (at STC) in the order of $10 \mathrm{~A}$ for bifacial technologies, while the rated open-circuit voltages can vary widely, depending on the number of series connected cells in the BIPV module.

In the prototype curtain wall BIPV element of Fig. 11, a typical 60-cell module with monocrystalline PESC cells was used with rated $V_{o c}$ of $38 \mathrm{~V}$ and $I_{s c}$ of $8.5 \mathrm{~A}$ [11]. In some designs it would however be more practical to have the same area as a transparent window in the upper part of the curtain wall element, and the PV module in the square area below, reducing the cell count to 36 and the rated $V_{o c}$ to about $23 \mathrm{~V}$. Furthermore, the lower part, which is now a triple glazing window, could also be a semi-transparent thin-film PV module of $164 \mathrm{~cm}$ by $109 \mathrm{~cm}$, with its own, dedicated MLC. As the TF cells are quite narrow, high rated $V_{o c}$ can build up quickly over rather short module widths. Moreover, CdTe cells have a typical $V_{o c}$ above $0.8 \mathrm{~V}$.

In the same test building as in [1], experimental semi-transparent CdTe BIPV windows of $60 \mathrm{~cm}$ by $120 \mathrm{~cm}$ and rated $V_{o c}$ of nearly $120 \mathrm{~V}$ are being monitored. SolarEdge P405 series power optimizers with $125 \mathrm{~V}$ input voltage limit were used in this setup but additional overvoltage protection circuits were needed to avoid MLC breakdown during winter, when the BIPV demonstrators 
are expected to exceed the $125 \mathrm{~V}$ limit. The rated $I_{s c}$ of those BIPV demos is quite low, in the order of $0.5 \mathrm{~A}$ at $\mathrm{STC}$, while the rated power is about $60 \mathrm{Wp}$, mainly due to the high series resistance. With TF BIPV, there is a module. The dimensions of the curtain wall are similar to the prototype which was developed and discussed in Section 2 .

Three cases with different PV technology are considered: regular c-Si, halfcell c-Si and CIGS thin film. Each of these cells has different dimensions and regular sized c-Si cells, assuming that the total surface (per two cells) remains 


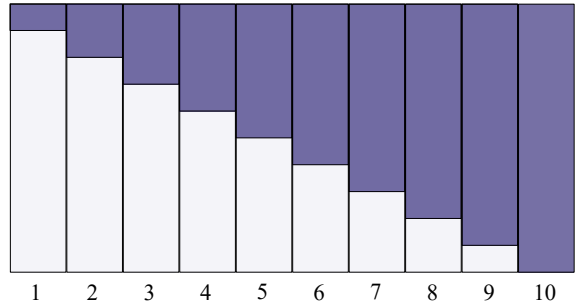

Front view

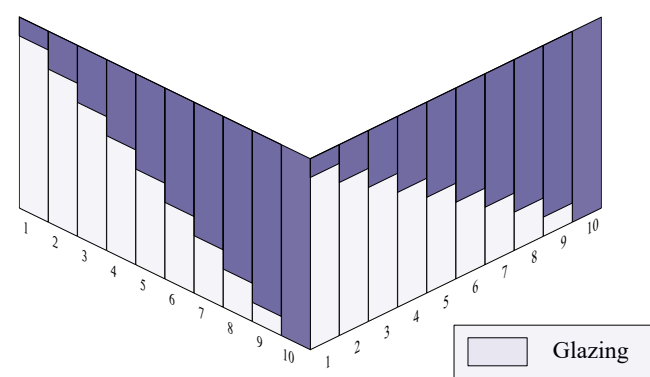

Corner view

PV

Figure 3: Appearance of one floor level of a case study building with BIPV curtain walls

the same whereas the voltage doubles and the current halves. To achieve a high output voltage, the cells are always assumed to be series connected. An overview is given in Table 1

A large spectrum of voltages and powers is covered over the different technologies and module dimensions. The output voltage ranges from $3 \mathrm{~V}$ up to $216 \mathrm{~V}$ whereas the power rating starts at $26 \mathrm{~W}$ and goes up to $452 \mathrm{~W}$. All cells are series connected and consequently $I_{M P P}$ remains the same per technology over the different module sizes. It changes over a more limited range from $1.54 \mathrm{~A}$ up to $8.3 \mathrm{~A}$ in the MPP. Note that high-efficiency monofacial and bifacial c-Si cells can output about $20-25 \%$ higher currents.

In the next section, the discrepancy between electrical output characteristics of BIPV as given in Table 1 will be compared to the input parameters of available MLCs as shown in Table 2 
Table 1: Electrical parameters at STC of the ten different BIPV modules in the case study façade. The modules are evaluated for c-Si, half cells c-Si and CIGS thin film technology of which the individual cells are series connected to achieve a max output voltage.

\begin{tabular}{|c|c|c|c|c|c|c|c|c|c|c|}
\hline $\begin{array}{c}\text { BIPV module } \\
\#\end{array}$ & 1 & 2 & 3 & 4 & 5 & 6 & 7 & 8 & 9 & 10 \\
\hline$S_{P V} / S_{t o t}(\%)$ & 10 & 20 & 30 & 40 & 50 & 60 & 70 & 80 & 90 & 100 \\
\hline \multicolumn{11}{|c|}{ Mono-crystalline c-Si cells } \\
\hline \multicolumn{11}{|c|}{ Cell dimensions: $157 \mathrm{~mm}$ by $157 \mathrm{~mm}$} \\
\hline Total \# cells & 6 & 18 & 30 & 36 & 48 & 60 & 72 & 78 & 90 & 102 \\
\hline$V_{o c}(\mathrm{~V})$ & 3,80 & 11,41 & 19,02 & 22,82 & 30,43 & 38,04 & 45,65 & 49,45 & 57,06 & 64,67 \\
\hline$I_{s c}(\mathrm{~A})$ & 8,86 & 8,86 & 8,86 & 8,86 & 8,86 & 8,86 & 8,86 & 8,86 & 8,86 & 8,86 \\
\hline$V_{M P P}(\mathrm{~V})$ & 3,21 & 9,63 & 16,05 & 19,26 & 25,68 & 32,10 & 38,52 & 41,73 & 48,15 & 54,57 \\
\hline$I_{M P P}(\mathrm{~A})$ & 8,30 & 8,30 & 8,30 & 8,30 & 8,30 & 8,30 & 8,30 & 8,30 & 8,30 & 8,30 \\
\hline$P_{M P P}(\mathrm{~W})$ & 26,64 & 79,92 & 133,20 & 159,84 & 213,12 & 266,40 & 319,68 & 346,32 & 399,60 & 452,88 \\
\hline
\end{tabular}

Cell dimensions: $1090 \mathrm{~mm}$ by $6 \mathrm{~mm}$

$\begin{array}{ccccccccccc}\text { Total \# cells } & 45 & 90 & 135 & 180 & 225 & 270 & 315 & 360 & 405 & 450 \\ V_{o c}(\mathrm{~V}) & 27,00 & 54,00 & 81,00 & 108,00 & 135,00 & 162,00 & 189,00 & 216,00 & 243,00 & 270,00 \\ I_{s c}(\mathrm{~A}) & 1,74 & 1,74 & 1,74 & 1,74 & 1,74 & 1,74 & 1,74 & 1,74 & 1,74 & 1,74 \\ V_{M P P}(\mathrm{~V}) & 21,60 & 43,20 & 64,80 & 86,40 & 108,00 & 129,60 & 151,20 & 172,80 & 194,40 & 216,00 \\ I_{M P P}(\mathrm{~A}) & 1,54 & 1,54 & 1,54 & 1,54 & 1,54 & 1,54 & 1,54 & 1,54 & 1,54 & 1,54 \\ P_{M P P}(\mathrm{~W}) & 33,11 & 66,22 & 99,33 & 132,44 & 165,54 & 198,65 & 231,76 & 264,87 & 297,98 & 331,09\end{array}$



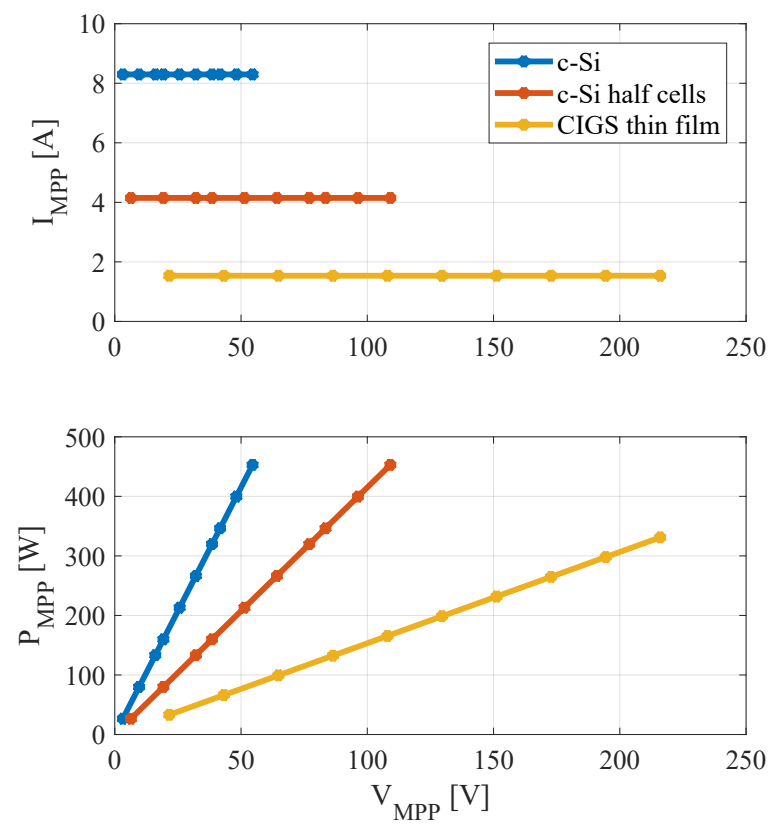

Figure 4: Graphical representation of $I_{M P P}$ and $P_{M P P}$ as a function of $V_{M P P}$ for the case study on the BIPV curtain wall module.

\section{Commercially available power electronics converters}

In this section, an overview of currently available commercial MLCs is given. Table 2 contains the relevant parameters to evaluate the integration of these converters in the BIPV module frame. Electrical parameters such as the nominal power, the MPPT voltage range and the efficiency are important to check the suitability with the expected voltage and current ranges that were discussed in Section 4 Table 3 provides more details on the cavity dimensions for converter embedment such that the converter dimensions can be compared to the available space.

To give a broad overview of the current state-of-the-art, Table 2 contains three types of MLC architectures: DC/AC micro-inverters (MIs), DC/DC Series Power Optimizers (SPOs) and DC/DC Parallel Power Optimizers (PPOs). The modular BIPV approach that was discussed in Section 2 is based on the 
utilization of the latter (PPO). However, using this larger dataset enables to draw more general conclusions on the integration possibilities for BIPV. 
Table 2: An overview of commercially available module-level converters

\begin{tabular}{|c|c|c|c|c|c|c|c|c|c|}
\hline Brand & Model & $\begin{array}{c}P_{\text {out }, \text { nom }} \\
(\mathrm{W})\end{array}$ & $V_{M P P T}(\mathrm{~V})$ & $\eta(\%)$ & $\begin{array}{l}\text { Temperature } \\
\text { range }\left({ }^{\circ} \mathrm{C}\right)\end{array}$ & $\begin{array}{c}\text { Dimensions } \\
\qquad\left(\mathrm{mm}^{3}\right)\end{array}$ & $\begin{array}{c}\text { Transformer } \\
\text { isolation? }\end{array}$ & $\begin{array}{c}\text { Power } \\
\text { density } \\
(\mathrm{W} / \mathrm{l})\end{array}$ & $\triangle V_{M P P T}(\mathrm{~V})$ \\
\hline \multicolumn{10}{|c|}{ Micro inverters $(D C / A C)$} \\
\hline Enphase & M250-60 & 250 & $16->48$ & 95,7 & $-40->+65$ & $179 \times 217 \times 28$ & Yes & 230 & 32 \\
\hline Enphase & M250-72 & 250 & $16->60$ & 95,7 & $-40->+65$ & $179 \times 217 \times 28$ & Yes & 230 & 44 \\
\hline Enphase & IQ7 & 240 & $16->48$ & 96,5 & $-40->+65$ & $212 \times 175 \times 30$ & Yes & 216 & 32 \\
\hline Enphase & IQ7+ & 290 & $16->60$ & 96,5 & $-40->+65$ & $212 \times 175 \times 30$ & Yes & 261 & 44 \\
\hline Enphase & $\mathrm{S} 230$ & 220 & $27->37$ & 95,8 & $-40->+65$ & $172 \times 175 \times 35$ & Yes & 209 & 10 \\
\hline Enphase & $\mathrm{S} 270$ & 260 & $27->48$ & 95,6 & $-40->+65$ & $172 \times 175 \times 35$ & Yes & 247 & 21 \\
\hline $\mathrm{ABB}$ & MICRO-0.25 & 250 & $12->60$ & 96 & $-40->+75$ & $266 \times 246 \times 35$ & Yes & 109 & 38 \\
\hline $\mathrm{ABB}$ & MICRO-0.3HV & 300 & $19->75$ & 96 & $-40->+75$ & $266 \times 246 \times 35$ & Yes & 131 & 56 \\
\hline SMA & SunnyBoy 240 & 230 & $23->45$ & 95,3 & $-40->+65$ & $188 \times 218 \times 44$ & Yes & 128 & 22 \\
\hline \multicolumn{10}{|c|}{ Series Power Optimizers $(D C / D C)$} \\
\hline SolarEdge & P300 & 300 & $8->48$ & 98,8 & $-40->+85$ & $139 \times 165 \times 41$ & No & 319 & 40 \\
\hline SolarEdge & P370 & 370 & $8->60$ & 98,8 & $-40->+85$ & $139 \times 165 \times 41$ & No & 393 & 52 \\
\hline SolarEdge & P500 & 500 & $8->80$ & 98,8 & $-40->+85$ & $139 \times 165 \times 49$ & No & 445 & 72 \\
\hline SolarEdge & $\mathrm{P} 404$ & 405 & $12,5->80$ & 98,8 & $-40->+85$ & $139 \times 165 \times 56$ & No & 315 & 67,5 \\
\hline SolarEdge & $\mathrm{P} 405$ & 405 & $12,5->105$ & 98,8 & $-40->+85$ & $128 \times 152 \times 50$ & No & 416 & 92,5 \\
\hline SolarEdge & $\mathrm{P} 505$ & 505 & $12,5->83$ & 98,8 & $-40->+85$ & $128 \times 152 \times 59$ & No & 440 & 70,5 \\
\hline Huawei & SUN2000P & 375 & $10->80$ & 99 & $-40->+85$ & $125 \times 85 \times 25,5$ & No & 1352 & 70 \\
\hline \multicolumn{10}{|c|}{ Parallel Power Optimizers $(D C / D C)$} \\
\hline Femtogrid & PO310 & 310 & $8->42$ & 97 & $-40->+65$ & $135 \times 225 \times 50$ & $N K$ & 204 & 34 \\
\hline Femtogrid & PO330 & 310 & $12->65$ & 96,4 & $-40->+65$ & $135 \times 225 \times 50$ & $N K$ & 204 & 53 \\
\hline
\end{tabular}


Table 3: Possible placement locations in the BIPV module frame and their dimensions

\begin{tabular}{ccc} 
Location & $\begin{array}{c}\text { Width } \\
(\mathrm{mm})\end{array}$ & $\begin{array}{c}\text { Height } \\
(\mathrm{mm})\end{array}$ \\
\hline 1 - Top, bottom and lateral profiles & 80 & 29 \\
2 - Middle profile & 150 & 75
\end{tabular}

265

\subsection{Dimensions}

At first, the outer dimensions of the converters are compared to the available space in the aluminum tubes of the BIPV module frame. Aluminum profiles with two different dimensions are being used, as shown in Fig. 6] and indicated in Table 3 .

Analyzing the dimensions of commerical MLCs reveals that none of the listed converters suits the size requirements imposed by the BIPV module on location one. There is however a strong size difference notable between MIs and PPOs on one hand and SPOs on the other hand. The power density of SPOs is a factor of 1,5 up to 2 higher. Two outliers are the Huawei SUN2000P with a power density over 1300 and the Femtogrid PO300. The low power density of the PO300 is because the datasheet only provides the dimensions with the installation bracket that surrounds the converter, leading to a size increase in both the length and width of the converter.

The trend of a higher power density for SPOs can be explained by several reasons, which mostly relate to the circuit topology of the converter. At first there is a difference in output. MIs produce an AC output voltage whereas SPOs/PPOs output DC. MIs utilize typically two conversion stages: DC/DC and DC/AC. This approach requires more components compared to PPOs where only a DC/DC conversion is performed. The notable size difference between PPOs and SPOs is due to the magnitude of the produced output voltage. For PPOs, the output is already directly compatible with the LVDC grid, of which the voltage ranges in the order of $350-400 \mathrm{~V}$. The maximum output of the majority of SPOs is limited to $40 \mathrm{~V}$, which is only around one tenth compared 
to the PPO output voltage. Only by combining them in series and adding an extra converter to control the output voltage allows to use them correctly.

Since the input $\left(V_{M P P T}\right)$ and output voltage of the SPOs are not far apart (e.g. a ratio of 0.15 to 1.24 for the SolarEdge P405), simpler power circuit topologies with fewer components can be used. For example, SolarEdge reports to use a buck-boost converter [34, which is one of the basic power conversion topologies having a minimal component count (5). In contrast, Enphase reports to use an interleaved flyback structure [35] which is required to boost the voltage to higher levels. This topology employs twice as many components if the coupled inductors are seen as two devices. The coupled inductors, sometimes referred to as flyback transformers, are often bulky components. As a consequence, both the efficiency and power density are lower compared to SPOs.

SPOs thus have the smallest dimensions of all considered options. Still, placement in the BIPV frame is not possible for location 1, where the dimensions exceed both the width and height requirement. For location 2, all SPOs fit in the frame and also the Femtogrid PO310 and PO330 are valid options.

\subsection{Efficiency}

The weighted efficiency $\eta$ is overall very high $(>95 \%)$ for all examined converters. SPOs show efficiencies that reach nearly $99 \%$. Their higher efficiency can again be explained by the small difference in input-to-output voltage they are designed for. As a consequence, high duty cycles resulting in higher switch conduction losses can be avoided. It is expected that a clear distinction in efficiency would be visible between the MIs and the PPOs since the latter avoid the conversion from DC to AC. This difference is however rather small, in the order of $0.4 \%$ between the PO330 and the ABB MIs. When comparing the former to the Enphase IQ7, the difference is even negative, $-0.1 \%$. This small difference can be due to a higher DC output voltage of the PPO compared to the internal DC bus voltage of the MIs. 


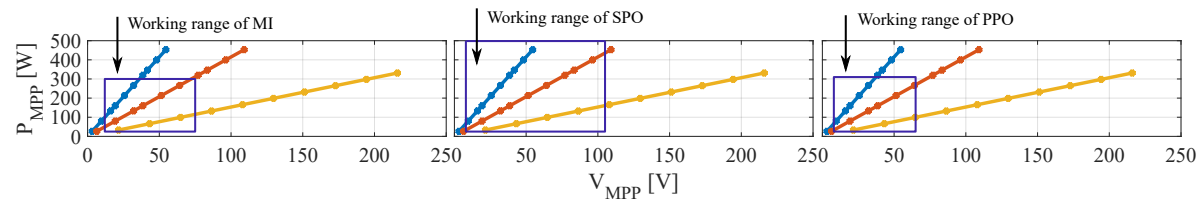

Figure 5: MPPT operating range of the investigated MIs, SPOs and PPOs indicated on a $V_{M P P}-P_{M P P}$ graph on which also the results of Table 1 are plotted. This figure indicates that a large portion of the BIPV modules is not covered by commercial MLCs. Mainly higher voltage TF panels do not match with the current commercial generation of MLCs.

\subsection{MPPT range and nominal power}

The MPPT range is an important parameter to compare converters as a wider range will increase the energy production, which decreases the payback time. When comparing the MPPT voltage range $\left(V_{M P P T}\right.$ and $\left.\triangle V_{M P P T}\right)$ a large difference is again observed between MIs/PPOs and SPOs. The latter outperform with several models where $\triangle V_{M P P T}$ is larger than $70 \mathrm{~V}$. A max $V_{M P P T}$ of $105 \mathrm{~V}$ is observed, which is very suited for mainstream BAPV but this limit is too low for BIPV, especially if TF is used. A graphical overview of the power and voltage range for the three converter types is given in Fig. 5. The purple lines indicate the operating range of the converters and the blue, orange and yellow lines represent respectively c-Si, half cell c-Si and TF technology and are derived from Table 1. SPOs span the widest range covering nearly the entire spectrum of c-Si and half cell c-Si. The working area of MIs and PPOs is nearly equal and requires expansion towards higher powers and voltages.

\subsection{Temperature range}

All MLCs of Table 2 employ passive cooling techniques. Active cooling is beneficial to increase the power density and efficiency of the converter. When lower component temperatures can be achieved, the conduction losses also decrease, leading to a higher overall efficiency. The power density can thus also increase, as power density and efficiency are closley related [36]. However, passive cooling is the preferred option from a cost and reliability perspective 37. Forced convection by using a fan is difficult from a reliability point-of-view as 
the fan has a limited lifetime due to its rotating parts. Liquid cooling is consid-

340 solution when not only the PV panel but also the electronics become part of the cooling circuit. The MLC could then benefit from the cooling system that is already available.

The majority of the investigated devices has an upper limit of $65^{\circ} \mathrm{C}$ at which starts to derate above $65^{\circ} \mathrm{C}$ to completely turn off at $75^{\circ} \mathrm{C}$. The SPOs have the highest dropout temperature, being $85^{\circ} \mathrm{C}$.

At our testsite where the BIPV prototype is installed, temperature and power measurements were constantly made. This data was used to verify if $65^{\circ} \mathrm{C}$ limit. The temperature data from a thermocouple placed at the 'TOP' location, as indicated in Fig. 6 was used. As can be seen from Fig. 8 there were several instances during May, June and July 2018 when this limit was crossed. These months have been selected since they represent the most critical conditions in terms of temperature. Converter shutdown due to overtemperature is a protection feature to increase the lifetime of the electronic components but this leads to a certain energy loss. The converter used at the test site is a Femtogrid PO330 PPO. Since this converter does not fit in the framework of the module, it was installed in a climizatized zone inside the test building where no overtemperature occurs. However, to quantify the energy loss related to high operating temperatures, the temperature measurements in the cavity were combined with the output power measurements of the PV module. When the threshold temperature of $65^{\circ} \mathrm{C}$ was passed, the output power was set to zero. Fig. 8 show the daily energy loss due to overtemperature. This was calculated using Eqn. 1 where $W_{\text {lost }, \%}$ is the daily energy loss in percent, $W_{\text {total }}$ is the total produced energy measured over one day and $W_{T>65}$ represents the energy 


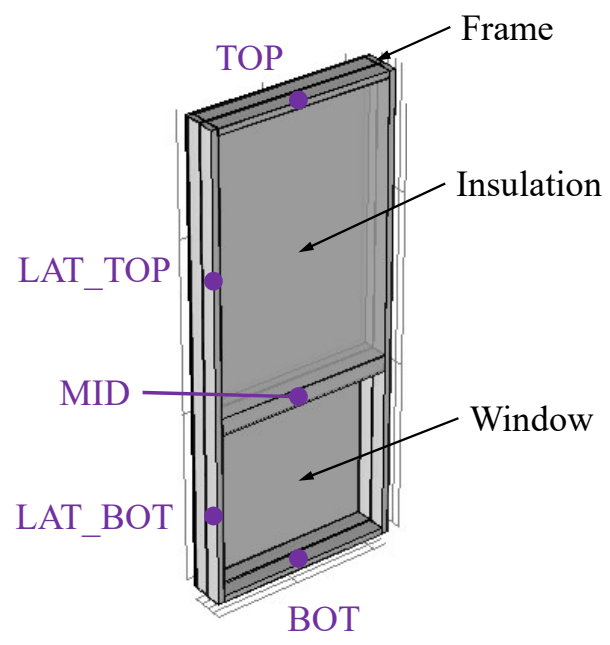

Figure 6: Angle view of the prototype BIPV curtain wall module with indication of the different possibilities for converter placement.

that is produced when the temperature is above the $65^{\circ} \mathrm{C}$ threshold.

$$
W_{\text {lost }, \%}=\frac{W_{\text {total }}-W_{T>65}}{W_{\text {total }, \text { dayn }}} \cdot 100
$$

Figure 7 shows an example of the measured power and temperature profile over one day and indicates the temperature crossings and the associated energy loss (grey). Mainly during July, large losses would occur with a temperature limit of $65^{\circ} \mathrm{C}$. Figure 8 indicates daily energy losses in the order of 20 to $50 \%$. Belgium has a temperate maritime climate. If the same structure would be evaluated in more southern areas with mediteranean (e.g. Italy) or subtropical climate (e.g. United Arabian Emirates), even higher energy loss needs to be considered during summer. This results in a longer payback time of the installation.

Further information regarding the impact of temperature on the reliability of BIPV MLCs can be found in [38]. 


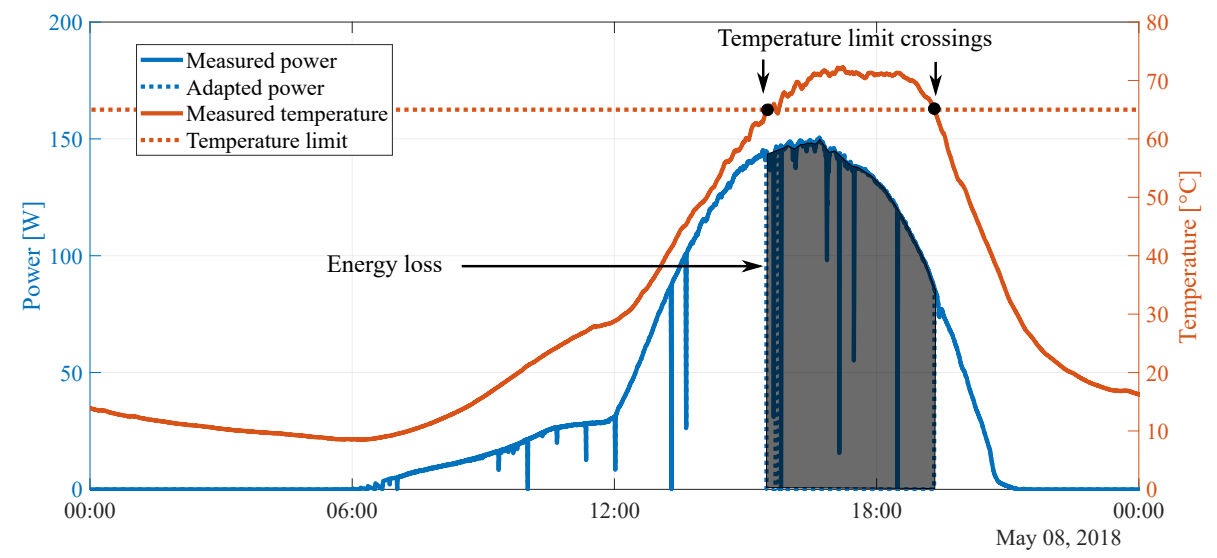

Figure 7: Measured temperature in the converter cavity and the anticipated energy loss due to overtemperature shutdown $\left(\mathrm{T}>65^{\circ} \mathrm{C}\right)$ shown on May $8,2018$.
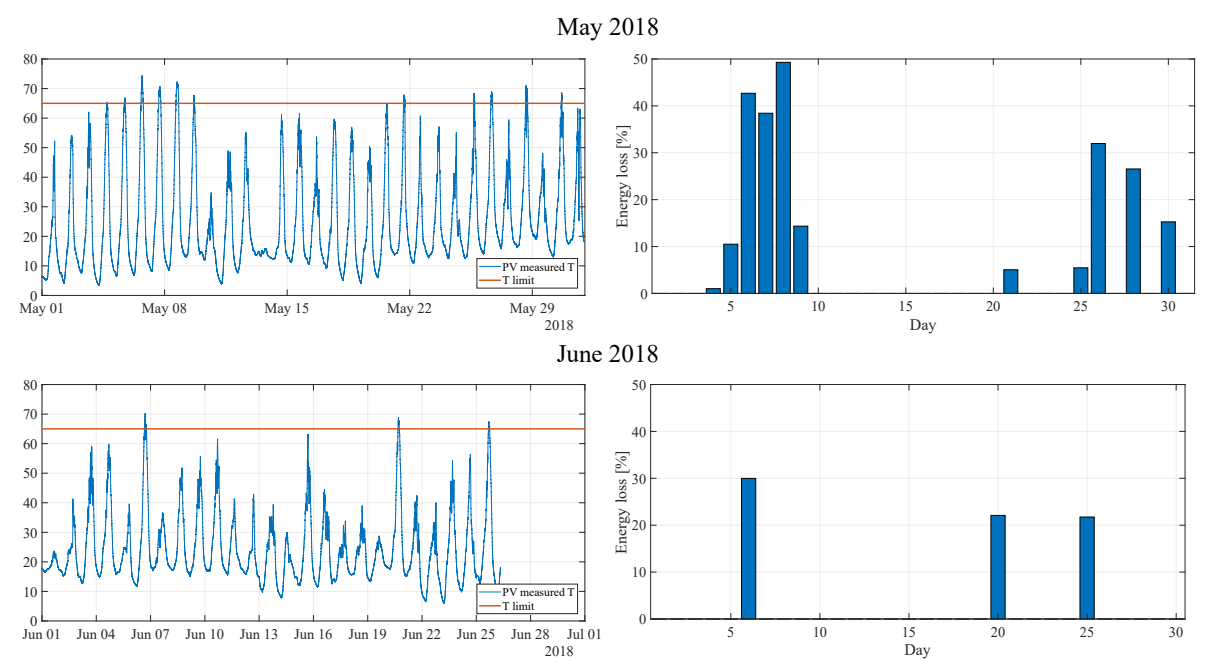

July 2018

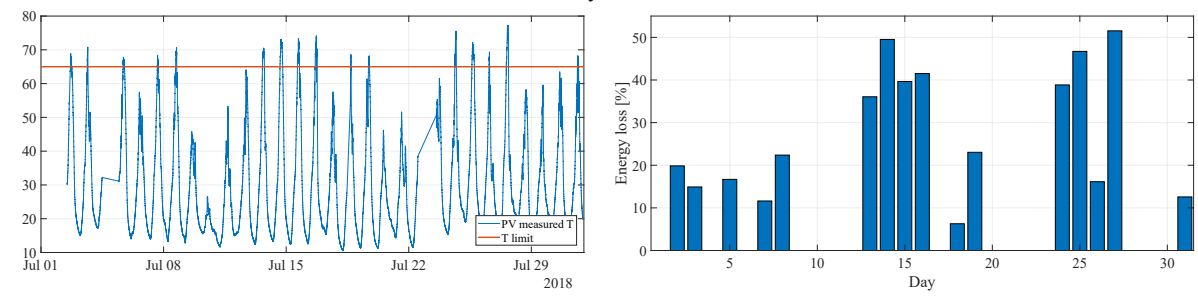

Figure 8: Measured temperature in the converter cavity and the anticipated energy loss due to overtemperature $\left(\mathrm{T}>65^{\circ} \mathrm{C}\right)$ shown over a period of three months. 


\section{Discussion of the results}

380 6.1. New product range for $M L C s$

As discussed in the case study of section 4. BIPV panels can produce a very wide variety of input voltages and currents. Today's generation of MLCs are optimised for mainstream 60-cell or 72-cell BAPV panels. In theory, they can be used at the low end of their MPPT and power range to serve the BIPV market. or the high end of the BIPV modules. Furthermore, current commercial models of converters do not have the required form factor to integrate them in the frame and thus make factory pre-installment more difficult or even impossible.

Given the large spectrum of output voltages and currents, it does not seem cost-effective and efficient to employ a one-converter-fits-it-all approach for the modular BIPV system. Instead this paper proposes to split up the PV output voltage/current/power in different categories, as shown in Fig. 9. This categorization has several positive consequences that will further facilitate the electrical design of the BIPV modules. can specificly target the BIPV market with a portfolio of products that are consistent with the output of BIPV modules. From Fig. 9, it can be seen that one product segment per PV technology is suggested. This is a consequence of the large differences in $V_{M P P}$ and $I_{M P P}$ that were observed. Class 1,2 and 3 correspond respectively with TF PV, c-Si half cells and regular c-Si PV cells. Furthermore, each class was subdivided three regions a, b and c. This was done to prevent extreme overdimensioning which would lead to very high costs when the same converter is used for very different power ratings. This could make the use of smaller BIPV panels uneconomical which is against the design philosophy that is proposed. The proposed classification should not be considered dogmatic but rather as a guideline in determining new MLCs for the BIPV market.

The classification and standardisation of BIPV MLCs is also important in the context of the increasing digitalisation of Architecture, Engineering and 


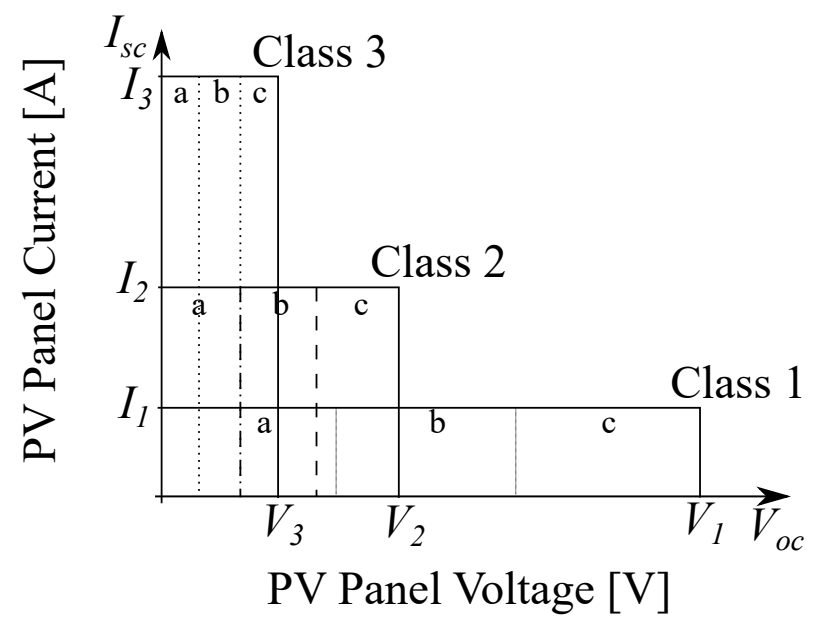

Figure 9: BIPV output characterisitics classification in different zones based on voltage and current limits. Alternatively, power limits can be considered.

Construction (AEC) processes. Building information modelling (BIM) supports the AEC digitalisation by integrating the roles of all stakeholders in a project. Being part of the building envelope, BIPV systems have also been contemplated in the BIM development [39. A BIM-based software tool called BIMsolar has been developed for the design and simulation of BIPV systems [40, in which the selection of inverters and MPP trackers appears as an integral part of the workflow.

\subsection{Preferred PV technology}

It was shown that the existing generation of MLCs that is available on the market does not match with the requirements of BIPV MLCs. An interesting question is which PV technology is most suited from a converter perspective to comply with the demands such as a high power density and a long converter lifetime.

The MLC is the bridge between the BIPV module and the LVDC grid. Its primary functions are to track the MPP and to increase the output voltage to the LVDC voltage level. There is no standardization yet on the exact voltage ${ }_{425}$ level of LVDC nanogrids in buildings but literature suggests unipolar voltages in 
the range of $350 \mathrm{up}$ to $400 \mathrm{~V}$ [1]. Note that twice this voltage can be available in a bipolar LVDC network to couple both low and high power appliances but the MLC is seen as a low power device and connected to only one network branch.

From a converter perspective, higher LVDC voltages are more challenging as the boost ratio has to increase. Converters with a low boost ratio or gain $\mathrm{G}$ achieve higher efficiencies and utilize a simpler converter topology. In practice, the border between high and low gain seems to be around $\mathrm{G}=5$ [42]. Below five, a standard boost converter can be used. Above five, more complex topologies with transformers, coupled inductors, switched inductors or voltage multiplier cells need to be used [43. When properly designed, these circuits still attain very high efficiencies but with a higher amount of components. This leads to increasing costs, lower power density and reduced reliability which are three important factors for BIPV MLCs.

440

When a $400 \mathrm{~V}$ grid is assumed and a standard boost converter is preferred, the BIPV output $V_{M P P}$ voltage needs to be higher than or equal to $80 \mathrm{~V}$. From Fig. 4 and Table 1. TF technology seems to be the most suitable technology from converter perspective due to the high output voltage and the resulting lower gains that are required to boost this voltage to the LVDC voltage level. 445 The limit of $V_{M P P} \geq 80 \mathrm{~V}$ already occurs when the ratio $S_{P V} / S_{t o t}$ is above $30 \%$. Also half cells are an interesting option, they reach the limit of $80 \mathrm{~V}$ when $S_{P V} / S_{t o t}$ is higher than $70 \%$. A third possibility would be the use of shingled solar cells where cells partly overlap at the edges. They bring the opportunity of producing higher voltages with c-Si, at the expense of higher manufacturing complexity of the PV generator [4, 45.

\section{Conclusions}

In this paper the concept of modular BIPV curtain walls was explained and the different aspects that relate to converter embedment are highlighted and investigated. 
Firstly, the electrical output parameters of curtain wall BIPV modules are investigated by means of a case study façade where three different PV technologies (c-Si, half-cell c-Si and CIGS thin film) and different ratios between the glass area and the PV area of the BIPV module are evaluated. This analysis showed that a wide variety of voltages and currents can be present in a BIPV curtain wall façade.

Secondly, an overview of commercially available MLCs is presented to check whether they are suited for embedment in façade BIPV modules. Therefore, they need to be compatible with the dimensional, thermal and electrical requirements. This analysis indicated that further progress is needed in MLC development. It calls for a new class of MLC with appropriate form factor, voltage range, and temperature tolerance, in order to fit the use case in facades optimally. Using a LVDC grid would help greatly in simplifying these converters, reducing the number of components, and lowering the price.

The paper concluded with a discussion on standardization of BIPV MLCs to further simplify and harmonize the design of the electrical installation and open the market for different converter design houses to make products that are easily interchangeable. Furthermore, TF or smaller c-Si cells seem the most suitable PV technology from a converter point of view. The high output voltage leads to lower gains resulting in more compact and more reliable converters.

\section{Acknowledgments}

This project receives the support of the European Union, the European Regional Development Fund ERDF, Flanders Innovation \& Entrepreneurship and the Province of Limburg. G. Van den Broeck is funded by a PhD grant of the Research Foundation Flanders (FWO). Furthermore, the authors would like to thank S. Dewallef from Soltech for his valuable input and comments. 


\section{References}

[1] E. Biyik, M. Araz, A. Hepbasli, M. Shahrestani, R. Yao, L. Shao, E. Essah, A. C. Oliveira, T. del Caño, E. Rico, J. L. Lechón, L. Andrade, A. Mendes, Y. B. Atl, A key review of building integrated photovoltaic (BIPV) systems, Engineering Science and Technology, an International Journal 20 (3) (2017) 833-858. doi:10.1016/j.jestch.2017.01.009. URL http://dx.doi.org/10.1016/j.jestch.2017.01.009

[2] J.-M. Moulin, BIPV and facades - look, it is a reality, in: EnergyVille BIPV workshop, Genk, Belgium, 8 December 2015.

[3] S. Dewallef, BIPV: from demonstration to implementation, in: Belgian BIPV workshop, Brussels, Belgium, 2017.

[4] European Commision, Towards an Integrated Strategic Energy Technology (SET) Plan: Accelerating the European Energy System Transformation.

[5] EU, Directive 2010/31/EU of the European Parliament and of the Council of 19 May 2010 on the energy performance of buildings (recast), Official Journal of the European Union (2010) 13-35doi:doi:10.3000/17252555. L_2010.153.eng.

[6] M. C. Brito, S. Freitas, S. Guimarães, C. Catita, P. Redweik, The importance of facades for the solar PV potential of a Mediterranean city 500 u using LiDAR data, Renewable Energy 111 (2017) 85-94. doi:10.1016/j. renene.2017.03.085

[7] I. H. Tseng, Y. T. Chien, C. H. Lin, C. H. Chang, K. C. Lin, C. Y. Huang, C. Y. Tsai, The developement of colorful tandem silicon thin film solar cells for see through BIPV applications, in: 2011 37th IEEE Photovoltaic 505 Specialists Conference, Seattle, WA, USA, pp. 000610-000611. doi:10. 1109/PVSC. 2011.6186027. 
[8] When PV modules are becoming real building elements: White solar module, a revolution for BIPV, in: 2015 IEEE 42nd Photovoltaic Specialist Conference, New Orleans, LA, USA, 14-19 June 2015, pp. 1-2. doi:10.1109/PVSC.2015.7355630.

[9] H. Yu, Q. Wang, C. Lu, C. Wei, The research on a new type of BIPV modules constructed by thin-film photovoltaic panel(or module)/PU/color organic-coated steel plate, in: 2014 40th IEEE Photovoltaic Specialist Conference, Denver, CO, USA, pp. 2724-2727. doi:10.1109/PVSC.2014. 6925492

[10] J. Goncalves, K. Spiliotis, J. Lehmann, K. Baert, J. Driesen, D. Saelens, Experimental validation of a bipv curtain wall model for building energy simulations., in: Advanced Building Skins Conference (ABS 2018), Bern, Switzerland, 1-2 October 2018.

${ }_{520}$ [11] J. Goncalves, J. Lehmann, G. Yordanov, W. Parys, K. Baert, D. Saelens, Experimental performance of a curtain wall bipv element under realistic boundary conditions, in: European Photovoltaic Solar Energy Conference (EUPVSEC 2018), Brussels, Belgium, 24-28 September 2018.

[12] J. Lehmann, W. Parys, J. Goncalves, K. Baert, D. Saelens, Experimental analysis of the performance of a bipv curtain wall component., in: Advanced Building Skins Conference (ABS 2017), Bern, Switzerland, 2-3 October 2017.

[13] G. Masson, BIPV Competitiveness and Market Potential, in: Belgian BIPV Workshop, Brussels, Belgium, 2017.

[14] D. Saelens, EnergyVille BIPV Roadmap, in: Belgian BIPV Workshop, Brussels, Belgium, 2017.

[15] M. Marc, Towards a broad BIPV deployment: what is needed? , in: EnergyVille BIPV workshop, Genk, Belgium, 2015. 
[16] N. M. Kumar, K. Sudhakar, M. Samykano, V. Jayaseelan, Bipv market

[18] N. Aste, C. D. Pero, F. Leonforte, The first Italian BIPV project : Case study and long-term performance analysis, Solar Energy 134 (2016) 340352. doi:10.1016/j.solener.2016.05.010

[22] R. Pillai, G. Aaditya, M. Mani, P. Ramamurthy, Cell ( module ) tema perature regulated performance of a building integrated photovoltaic sys-

560 tam in tropical conditions, Renewable Energy 72 (2014) 140-148. doi: 10.1016/j.renene.2014.06.023.

URL http://dx.doi.org/10.1016/j.renene.2014.06.023 
[23] E. A. Essah, A. Rodriguez, N. Glover, Assessing the performance of a building integrated BP c-Si PV system, Renewable Energy 73 (2015) 3645. doi:10.1016/j.renene.2014.04.002.

URL http://dx.doi.org/10.1016/j.renene.2014.04.002

[24] Y. Brigitte, F. Sauzedde, B. Boillot, S. Boddaert, Development of a building integrated solar photovoltaic thermal hybrid drying system, Energy 128. doi:10.1016/j.energy.2017.04.062.

[25] A. J. Aristizábal, C. A. Páez, Experimental investigation of the performance of $6 \mathrm{~kW}$ BIPV system applied in laboratory building, Energy and Buildings 152 (2017) (2018) 1-10. doi:https://doi.org/10.1016/j. enbuild.2017.07.030

[26] H.-j. Chen, C.-m. Shu, C.-m. Chiang, S.-k. Lee, Energy Procedia The Indoor Thermal Research of the HCRI-BIPV Smart Window, Energy Procedia 12 (2011) 593-600. doi:10.1016/j.egypro.2011.10.080. URL http://dx.doi.org/10.1016/j.egypro.2011.10.080

[27] S. Wittkopf, S. Valliappan, L. Liu, K. Seng, S. Chye, J. Cheng, Analytical n performance monitoring of a $142.5 \mathrm{~kW}$ p grid-connected rooftop BIPV system in Singapore, Renewable Energy 47 (October 2009) (2012) 9-20. doi:10.1016/j.renene.2012.03.034 URL http://dx.doi .org/10.1016/j.renene.2012.03.034

[28] C. Zomer, A. Nobre, P. Cassatella, T. Reindl, R. Rther, The balance between aesthetics and performance in building-integrated photovoltaics in the tropics, Progress in Photovoltaics: Research and Applications 22 (7) (2014) 744-756, pIP-13-157.R1. doi:10.1002/pip.2430.

[29] P. Macé, D. Larsson, J. Benson, Transition towards Sound BIPV Business Models - Inventory on Existing Business Models, Opportunities and Issues for BIPV, Tech. rep., International Energy Agency - Photovoltaic Power Systems Programme (Technical Report; International Energy AgencyPhotovoltaic Power Systems Programme: Paris, France, 2018). 
[30] G. V. D. Broeck, W. Parys, H. Goverde, S. V. D. Putten, J. Poortmans, J. Driesen, K. Baert, Experimental analysis of the performance of facadeintegrated BIPV in different configurations, in: 32nd European Photovoltaic Solar Energy Conference and Exhibition, Munich, Germany, 2016, pp. 1-5.

[31] M. A. Gross, S. O. Martin, N. M. Pearsall, Estimation of output enhancement of a partially shaded bipv array by the use of ac modules, in: Conference Record of the Twenty Sixth IEEE Photovoltaic Specialists Conference, Anaheim, CA, USA, 29 September-3 October 1997, pp. 1381-1384. doi:10.1109/PVSC.1997.654348.

[32] N. Van der Borg, M. Jansen, Energy loss due to shading in a bipv application, in: Proceedings of 3rd World Conference on Photovoltaic Energy Conversion, Osaka, Japan, Vol. 3, 2003, pp. 2220-2222.

[33] B. Liu, S. Duan, T. Cai, Photovoltaic DC-building-module-based BIPV system-concept and design considerations, IEEE Transactions on Power Electronics 26 (5) (2011) 1418-1429. doi:10.1109/TPEL.2010.2085087.

[34] Technical Note - SolarEdge Fixed String Voltage, Concept of Operation, Tech. rep., Solaredge Israel (2016).

[35] M. Fornage, M. Hassan-Ali, T. H. Omar, Method and apparatus for providing power conversion using an interleaved flyback converter with automatic balancing (2013). arXiv:arXiv:1208.5721, doi:10.1016/j . (73).

[36] J. W. Kolar, U. Drofenik, J. Biela, M. L. Heldwein, H. Ertl, T. Friedli, S. D. Round, Pwm converter power density barriers, in: 2007 Power Conversion 615 ㅁ Conference - Nagoya, 2007, pp. P-9-P-29. doi:10.1109/PCCON.2007. 372914 .

[37] S. Ravyts, M. D. Vecchia, J. Zwysen, G. Van den Broeck, J. Driesen, Study on a cascaded dc-dc converter for use in building-integrated photovoltaics, 
in: 2018 IEEE Texas Power and Energy Conference (TPEC), 2018, pp.

[38] W. Van De Sande, K. Spiliotis, J. Gonçalves, S. Ravyts, J. Driesen, D. Saelens, M. Daenen, Reliability comparison of a DC-DC converter placed in Building-Integrated Photovoltaic module frames, in: International conference on renewable energy research and applications (ICRERA), Paris, France, 2018, pp. 1-5.

[39] P. Bonomo, E. Saretta, F. Frontini, Towards the implementation of a BIMbased approach in BIPV sector, in: Advanced Building Skins Conference, Bern, Switzerland, 2018.

[40] P. Alamy, V. K. Nguyen, Pvsites software tools for bim-based design and simulation of bipv systems, in: Advanced Building Skins Conference, Bern, Switzerland, 2018.

[41] E. Rodriguez-Diaz, F. Chen, J. C. Vasquez, J. M. Guerrero, R. Burgos, D. Boroyevich, Voltage-Level Selection of Future Two-Level LVdc Distribution Grids: A Compromise between Grid Compatibiliy, Safety, and Efficiency, IEEE Electrification Magazine 4 (2) (2016) 20-28. doi: 10.1109/MELE. 2016.2543979.

[42] R.W. Erickson and D. Maksimovic, Fundamentals of Power Electronics (Second Edition), Springer, 2001.

[43] Step-Up DC-DC converters: A comprehensive review of voltage-boosting techniques, topologies, and applications, IEEE Transactions on Power Electronics 32 (12) (2017) 9143-9178. doi:10.1109/TPEL.2017.2652318

[44] A. Mondon, N. Klasen, E. Fokuhl, M. Mittag, M. Heinrich, H. Wirth, Comparison of Layouts for Shingled Bifacial PV modules in Terms of Power Output, Cell-to-Module Ratio and Bifaciality, in: 35th European PV Solar

645 Energy Conference and Exhibition, Brussels, Belgium, pp. 1531-1536. doi: 10.4229/35thEUPVSEC20182018-5B0.9.3. 
[45] M. Mittag, T. Zech, M. Wiese, D. Bläsi, M. Ebert, H. Wirth, E. Systems, Cell-to-Module (CTM) Analysis for Photovoltaic Modules with Shingled Solar Cells, in: 44th IEEE Photovoltaic Specialist Conference, Washington 